\title{
Leishmania braziliensis: ESTUDO EPIDEMIOLÓGICO NA REGIÃO NORTE DO PARANÁ
}

\section{E.A. CASTRO ${ }^{1}$; V. THOMAZ-SOCCOL ${ }^{1}$; N. MEMBRIVE ${ }^{2}$; E. LUZ}

${ }^{1}$ Laboratório de Parasitologia Molecular, Departamento de Patologia Básica, Universidade Federal do Paraná. ${ }^{2}$ Laboratório de Entomologia da Regional de Arapongas, Fundação Nacional de Saúde, Arapongas Paraná.

A leishmaniose é conhecida no Estado do Paraná nas regiões Norte Velho e Norte Novo e no Vale da Ribeira. Na época do povoamento do Estado, na região norte, a leishmaniose apresentou-se de forma epidêmica. Nos anos 50, com a campanha de erradicação da malária, esta protozoose teve uma significativa redução do número de casos clínicos. Nos anos 80 , a leishmaniose volta a se apresentar de forma epidêmica. Neste trabalho, os autores apresentam resultados de 5 anos de pesquisa na região norte, especificamente na $16^{\mathrm{a}}$ Regional de Saúde do Estado (compreendendo em média 25 Municípios). Um total de 354 pacientes foram examinados e 201 estavam positivos para leishmaniose cutânea, sendo que destas $90,1 \%$ eram lesões clássicas, $6 \%$ apresentavam lesões múltiplas e 3,9\% eram formas muco-cutâneas. As lesões foram encontradas preferencialmente nas extremidades (54\% nas pernas e $32 \%$ nos braços). $63.6 \%$ dos pacientes pertenciam ao sexo masculino e $36.4 \%$ ao sexo feminino. $77,2 \%$ eram adultos e $22,8 \%$ eram crianças. O diagnóstico foi estabelecido pelo método parasitológico (esfregaço e cultura celular). Cepas de Leishmania foram isoladas em meios NNN e Tobbie \& Evans. As cepas foram identificadas através de eletroforese utilizando 13 locus isoenzimáticos e caracterizadas como Leishmania (Viannia) braziliensis. No estudo da fauna de flebotomíneos as seguintes espécies foram capturadas: Lutzomyia whitmani (70\%), Lu. pessoai (8\%), Lu. migonei (7\%), Lu. fischeri (5\%), Lu. monticola $(3,5 \%)$, Lu. intermedia (3\%), Lu. lanei $(<1 \%)$, Lu. shanoni $(<1 \%)$, Lu. alphabetica $(<1 \%)$, Lu. firmatoi $(<1 \%)$., Lu. correalimai (1\%), Lu. missionensis (<1\%), Lu. corumbaensis $(<1 \%)$ e Lu. longipenis $(<1 \%)$. 